\title{
Determinantes das escolhas alimentares em restaurantes à la carte
}

\author{
Food choices determinants in à la carte restaurants
}

\author{
Rita de Cássia Ribeiro* \\ Carolina Fagundes Silveira Teixeira** \\ Rita de Cássia Marques*** \\ Edgar Gastón Jacobs Flores Filho****
}

\begin{abstract}
Resumo
É notória a expansão do número de restaurantes, em especial os à la carte, e a análise dos determinantes das escolhas alimentares nesses ambientes pode sugerir mudanças nos hábitos alimentares. Nesse sentido, o objetivo dessa pesquisa foi caracterizar usuários de restaurantes à la carte e analisar os fatores relacionados às tomadas de decisão para o consumo das diferentes opções culinárias ofertadas nesses restaurantes. Os dados foram coletados a partir da criação de um sítio eletrônico com perguntas relacionadas às escolhas alimentares de pessoas que frequentavam restaurantes à la carte, e de visitas a estabelecimentos dessa categoria para investigar os menus. Além da análise descritiva, foi verificada a influência do sexo e escolaridade sobre as variáveis relacionadas às escolhas alimentares. Para analisar a correlação entre idade e frequência mensal a esses estabelecimentos, foi utilizado o coeficiente e teste de correlação, e para apresentação e comparação dos atributos mais presentes nos menus, foram utilizados a média e intervalos de 95\% de confiança. Verificou-se que o sexo, idade e escolaridade conduzem, de maneira significativa, a tomada de decisão dos usuários de restaurantes à la carte. As informações como preço e descrição dos ingredientes estavam presentes na maioria dos estabelecimentos, mas os usuários consideravam, além de suas preferências, as características sensoriais dos pratos, as quais eram pobremente exploradas nos menus. Idas a restaurantes dessa categoria apontam para a aquisição de um novo hábito e sugerem mudanças no padrão alimentar.
\end{abstract}

Palavras-chave: Restaurantes. Refeições. Comportamento de Escolha.

\begin{abstract}
It is remarkable the increase in the number of restaurants, especially à la carte ones, and the analysis of the determinants of food choices in these environments may suggest changes in the food pattern. In this sense, the aim of the present study was to characterize users of à la carte restaurants and analyze the factors related to the decisions made regarding consumption of different culinary options offered in these establishments. Data were collected from an electronic site created with questions related to food choices of people that go habitually to à la carte restaurants and by visits to restaurants in this category to investigate the menus. In addition to the descriptive analyses, sex and schooling influence on the variables related to the food choices were verified. In order to analyze the correlation between age and monthly use of these establishments, a correlation coefficient was calculated. For the presentation and comparison of the most identified attributes in the menus a median and $95 \%$ confidence intervals were used. It was verified that sex, age and schooling affected in a significant way the decisions made by the users of these à la carte restaurants. Information such as price and ingredient descriptions was present in most establishments, but the users considered, in addition to their preferences, the sensory characteristics of the plates, an aspect poorly explored in the menus. Use of restaurants in this category may indicate the acquisition of a new habit and suggest changes in the users' food patterns.
\end{abstract}

Keywords: Restaurants. Meals. Choice Behavior.

DOI: 10.15343/0104-7809.20143803314324

* Departamento de Nutrição, Universidade Federal de Minas Gerais, Belo Horizonte-MG, Brasil. E-mail: ritagastronomia@hotmail.com; ritaribeiro@ufmg.br

** Universidade Federal de Minas Gerais, Belo Horizonte-MG, Brasil.

*** Departamento de Enfermagem Aplicada, Universidade Federal de Minas Gerais, Belo Horizonte-MG, Brasil.

**** Faculdade de Direito, Pontifícia Universidade Católica de Minas Gerais, Belo Horizonte-MG, Brasil.

Os autores declaram não haver conflitos de interesse. 


\section{INTRODUC̣ÃO}

A Pesquisa de Orçamentos Familiares 20082009 revelou que, do valor mensal destinado pelas famílias brasileiras para a alimentação, 33,1\%, em média, eram gastos com alimentação fora do domicilio ${ }^{1}$. Tal pesquisa reflete as transformações ocorridas no modo como os indivíduos se alimentam, e a necessidade de adaptação das pessoas ao meio urbano impulsiona-os a ajustarem suas práticas alimentares a questões de cunho cultural, espacial e financeiro ${ }^{2-5}$.

Nesse contexto, nota-se a crescente expansão do setor de restaurantes. Segundo pesquisa realizada pela Associação Brasileira das Empresas de Refeições Coletivas ${ }^{6}$, o número de refeições coletivas / dia obteve, no período de 2008 a 2012, um aumento de 131,3\%. De maneira similar, de acordo com dados divulgados pela Associação Brasileira das Indústrias da Alimentação ${ }^{7}$, o setor de food service passou de um faturamento de 58,2 bilhões de reais, no ano de 2008, para 100,5 bilhões de reais, no ano de 2012, o que representa um crescimento de 58\% nos últimos cinco anos. Destaca-se que a contribuição média anual do setor de alimentação para o Produto Interno Bruto brasileiro é de 9,0\%, fazendo desse setor um dos mais relevantes para a geração de saldo comercial positivo na economia brasileira'.

O recente crescimento econômico observado nos países em desenvolvimento, entre eles o Brasil, permite uma maior mobilidade social $^{8,9}$. As classes sociais que anteriormente não possuíam condições de usufruir de atividades relacionadas ao lazer, entre elas as idas a restaurantes sofisticados, agora detêm maior acessibilidade a esse tipo de estabelecimento.

Concomitantemente a essa expansão e ao contínuo desenvolvimento econômico do país, com consequente intensificação dos hábitos alimentares fora de casa, observa-se, no Brasil, a valorização de algumas tendências de alimentação. Entre elas, é evidente a importância dada à sensorialidade e prazer durante as refeições, a qual relaciona-se, principalmente, com o aumento do nível de educação, informação e renda da população ${ }^{10}$.
Deve-se atentar, também, à ascensão da gastronomia como fenômeno socioeconômico, uma vez que existe a procura por produtos e ingredientes de qualidade, com garantia de origem, visualmente atrativos e regionais. Torna-se evidente a forte tendência à valorização dos elementos que tornam o ato de comer um exercício de prazer e de manifestação cultural.

Por isso, acredita-se que os restaurantes, com destaque aos à la carte, tornaram-se palco de manifestações artísticas, comandadas pelos chefes de cozinha, e não é em vão que é o segmento que aparece como terceira opção de lugar onde os consumidores costumam fazer suas refeições fora do $\operatorname{lar}^{10}$.

Por outro lado, a ciência não tem acompanhado esse fenômeno, visto a escassez de pesquisas nessa área. Conhecer o tipo de frequentadores de restaurantes à la carte - principal nicho de exercício da gastronomia -, bem como os determinantes das escolhas alimentares nesses ambientes, é extremamente relevante, uma vez que permite o melhoramento constante das práticas envolvidas na alimentação fora do domicílio, além de sugerir mudanças importantes nos hábitos alimentares.

Ressalta-se que a escolha alimentar é um processo dinâmico e é construída por diversos determinantes. $\mathrm{O}$ ato da escolha está vinculado a fatores do meio ambiente, da história individual e da personalidade refletida em valores pessoais, bem como é influenciado por fatores biológicos, econômicos, físicos, sociais e psicológicos ${ }^{11}$.

Portanto, na presente pesquisa, procurou-se caracterizar usuários de restaurantes à la carte e analisar os fatores relacionados às tomadas de decisão para o consumo das diferentes opções culinárias ofertadas nesses locais.

\section{MÉTODO}

Trata-se de uma pesquisa descritiva e transversal, em que a coleta de dados partiu da criação de um sítio eletrônico ${ }^{\mathrm{a}}$ com perguntas relacionadas às escolhas alimentares de pessoas que frequentavam restaurantes à la carte. Paralelamente a essa etapa, visitaram- 
se restaurantes dessa categoria localizados na região centro-sul de Belo Horizonte-MG, independentemente de sua temática culinária, para verificar as informações presentes nos menus, de maneira a permitir o cruzamento de informações. Nesses restaurantes, foram distribuídos panfletos com informações sobre a pesquisa e foi solicitado aos usuários que acessassem o questionário eletrônico entre setembro e novembro de 2012 e participassem dessa investigação científica. Foram estabelecidos como critérios de inclusão pessoas com 19 anos ou mais e que frequentassem restaurantes dessa categoria pelo menos uma vez ao mês. Essa pesquisa foi aprovada por Comitê de Ética em Pesquisa da Universidade Federal de Minas Gerais, sob n CAAE: 0578.0.203.000-11.

Em relação ao plano amostral dos usuários dos restaurantes, para calcular o tamanho da amostra, na intenção de verificar a correlação existente entre idade e frequência de idas a restaurantes à la carte ao mês com as variáveis quantitativas relacionadas às tomadas de decisão, foi utilizada a proposta de Lachin ${ }^{12}$. Para a comparação de dois grupos em respostas contínuas para amostras independentes e para verificar a diferença de proporções entre as variáveis sexo e escolaridade com as variáveis qualitativas do estudo, foi utilizada a metodologia proposta por Fleiss ${ }^{13}$, para comparações de dois grupos em respostas binárias para dados independentes. Portanto, considerando um nível de significância de 5\% e um tamanho do efeito médio, tem-se que 105 questionários válidos representaria uma amostra com poder maior que $80 \%$ para os testes de correlação e maior que $70 \%$ para os testes de comparação de médias e comparações de proporção.

Além da análise descritiva, foi verificada a influência do sexo e escolaridade sobre as variáveis relacionadas às tomadas de decisão dos usuários desses restaurantes. Para isso, foi utilizado o teste qui-Quadrado para as variáveis qualitativas e o teste de Mann-Whitney para as variáveis quantitativas, de acordo com Hollander e Wolfe $^{14}$. Para analisar a correlação entre idade e frequência mensal a esses estabelecimentos gastronômicos, foi utilizado o coeficiente e teste de correlação de Spearman ${ }^{15}$.
Para a classificação dos itens importantes para tomada de decisão do usuário foi utilizada uma escala de importância limitada entre 0 e 1 , sendo $0=$ "o item não esteve entre as três escolhas mais importantes", 0,333 = "o item foi a terceira escolha mais importante", 0,667 = "o item foi a segunda escolha mais importante" e 1 = "o item foi a primeira escolha mais importante". Dessa forma, valores médios próximos a 1 significam que, em média, o item tende a ser a primeira escolha mais importante, enquanto que valores próximos a 0 significa que, em média, o item tende a não estar entre as três escolhas mais importantes.

Para o cálculo da amostra de restaurantes que participariam da pesquisa utilizou-se o método para estimação de proporções para populações finitas conforme Bolfarine e Bussab ${ }^{16}$, em que se adotou um $\mathrm{n}=48$ restaurantes à la carte presentes na região centro-sul de Belo Horizonte, a qual possui a maior concentração de estabelecimentos gastronômicos. Assim, a análise de menus em 39 restaurantes partiu de uma margem de erro de 7\% e nível de significância de 5\%.

Para realizar as análises dos atributos presentes ou não nos cardápios dos restaurantes, optou-se por utilizar uma escala numérica de 0 a 1 para representar a presença dos atributos, sendo 0 = "não presente", 0,5 = "em parte" e 1 = "presente". Dessa forma, valores médios próximos de 1 significam que, em média, os restaurantes têm aquele atributo mais presente no cardápio, enquanto valores próximos a 0 significam que, em média, os restaurantes não apresentam aquela informação. Para apresentação e comparação dos atributos mais presentes, foram utilizados a média e intervalos de 95\% de confiança via metodologia bootstrap. O software utilizado nessas análises foi o $R$, versão 2.15.3.

\section{RESULTADOS}

\section{Análise descritiva}

Na Tabela 1, é apresentada a análise descritiva das informações obtidas dos usuários de restaurantes à la carte por meio do sítio eletrônico criado para essa pesquisa. 
Tabela 1. Frequência para as variáveis qualitativas que compõem o perfil e comportamento dos consumidores. Belo Horizonte-MG, Brasil, 2012

\begin{tabular}{|c|c|c|c|}
\hline Variáveis & Fatores & Frequência absoluta & $\begin{array}{c}\text { Frequência } \\
\text { relativa }\end{array}$ \\
\hline \multirow{3}{*}{ Sexo } & Feminino & 76 & $72,4 \%$ \\
\hline & Masculino & 29 & $27,6 \%$ \\
\hline & Total & 105 & $100,0 \%$ \\
\hline \multirow{3}{*}{ Escolaridade } & Superior Incompleto & 32 & $30,5 \%$ \\
\hline & Superior completo & 73 & $69,5 \%$ \\
\hline & Total & 105 & $100,0 \%$ \\
\hline \multirow{3}{*}{ Informações no cardápio são suficientes? } & Não & 50 & $47,6 \%$ \\
\hline & Sim & 55 & $52,4 \%$ \\
\hline & Total & 105 & $100,0 \%$ \\
\hline \multirow{3}{*}{$\begin{array}{l}\text { Você analisa todo o cardápio ou apenas os } \\
\text { itens de seu maior interesse? }\end{array}$} & Maior interesse & 28 & $26,7 \%$ \\
\hline & Todo o cardápio & 77 & $73,3 \%$ \\
\hline & Total & 105 & $100,0 \%$ \\
\hline \multirow{3}{*}{$\begin{array}{l}\text { Você compreende todos os termos do cardá- } \\
\text { pio? }\end{array}$} & Não & 54 & $51,4 \%$ \\
\hline & Sim & 51 & $48,6 \%$ \\
\hline & Total & 105 & $100,0 \%$ \\
\hline \multirow{3}{*}{ Você consulta o maître? } & Não & 34 & $32,4 \%$ \\
\hline & Sim & 71 & $67,6 \%$ \\
\hline & Total & 105 & $100,0 \%$ \\
\hline \multirow{10}{*}{$\begin{array}{l}\text { O item mais importante para a escolha do } \\
\text { prato }\end{array}$} & Ingredientes & 37 & $35,2 \%$ \\
\hline & Sua preferência & 34 & $32,4 \%$ \\
\hline & Descrição & 13 & $12,4 \%$ \\
\hline & Aspectos sensoriais & 11 & $10,5 \%$ \\
\hline & Preço & 4 & $3,8 \%$ \\
\hline & Aspectos nutricionais & 2 & $1,9 \%$ \\
\hline & Tamanho & 2 & $1,9 \%$ \\
\hline & Foto do prato & 1 & $1,0 \%$ \\
\hline & Sugestão do chefe & 1 & $1,0 \%$ \\
\hline & Total & 105 & $100,0 \%$ \\
\hline \multirow{9}{*}{$\begin{array}{l}\text { O segundo item mais importante para a esco- } \\
\text { lha do prato }\end{array}$} & Ingredientes & 31 & $29,8 \%$ \\
\hline & Aspectos sensoriais & 23 & $22,1 \%$ \\
\hline & Sua preferência & 17 & $16,3 \%$ \\
\hline & Aspectos nutricionais & 10 & $9,6 \%$ \\
\hline & Preço & 10 & $9,6 \%$ \\
\hline & Descrição & 6 & $5,8 \%$ \\
\hline & Tamanho & 5 & $4,8 \%$ \\
\hline & Sugestão do chefe & 2 & $1,9 \%$ \\
\hline & Total & 104 & $100,0 \%$ \\
\hline \multirow{11}{*}{$\begin{array}{l}\text { O terceiro item mais importante para a esco- } \\
\text { Iha do prato }\end{array}$} & Preço & 28 & $26,9 \%$ \\
\hline & Sugestão do chefe & 16 & $15,4 \%$ \\
\hline & Sua preferência & 13 & $12,5 \%$ \\
\hline & Aspectos sensoriais & 9 & $8,7 \%$ \\
\hline & Ingredientes & 8 & $7,7 \%$ \\
\hline & Métodos de cocção & 8 & $7,7 \%$ \\
\hline & Aspectos nutricionais & 7 & $6,7 \%$ \\
\hline & Descrição & 5 & $4,8 \%$ \\
\hline & Foto do prato & 5 & $4,8 \%$ \\
\hline & Tamanho & 5 & $4,8 \%$ \\
\hline & Total & 104 & $100,0 \%$ \\
\hline
\end{tabular}


Tabela 1. Frequência para as variáveis qualitativas que compõem o perfil e comportamento dos consumidores. Belo Horizonte-MG, Brasil, 2012 (continução)

\begin{tabular}{llcc}
\hline Variáveis & Fatores & Frequência absoluta & $\begin{array}{c}\text { Frequência } \\
\text { relativa }\end{array}$ \\
\hline \multirow{2}{*}{$\begin{array}{l}\text { Você tenta reproduzir o prato que escolheu } \\
\text { em casa? }\end{array}$} & Não & 54 & $51,9 \%$ \\
& Sim & 50 & $48,1 \%$ \\
\hline & Total & 104 & $100,0 \%$ \\
& A gastronomia é uma experiência vivencia- & 3 & $5,6 \%$ \\
da nos restaurantes & 14 & $25,9 \%$ \\
Você não tenta reproduzir o prato em casa & Não domina as técnicas de preparo & 11 & $20,4 \%$ \\
porque: & Não tem o hábito de cozinhar em casa & 21 & $38,9 \%$ \\
& Nenhuma das alternativas acima & 5 & $9,3 \%$ \\
\hline
\end{tabular}

A idade média dos participantes foi de 37,5 anos $( \pm 11,6)$, com mínimo de 19 e máximo de 67 anos (Tabela 2), e a frequência média de idas aos restaurantes à la carte foi de 4,1 vezes por mês.

Tabela 2. Idade dos participantes da pesquisa. Belo Horizonte-MG, Brasil, 2012

\begin{tabular}{lcccccccc}
\hline Variável & $\mathbf{n}$ & Média & D.P. & Mín. & $\mathbf{1}^{\circ} \mathbf{Q}$ & $\mathbf{2}^{\circ} \mathbf{Q}$ & $\mathbf{3}^{\circ} \mathbf{Q}$ & Máx. \\
\hline Idade & 105 & 37,45 & 11,63 & 19,0 & 28,0 & 36,0 & 46,0 & 67,0 \\
\hline
\end{tabular}

\section{Análise estatística}

Foi verificada a influência do sexo, idade, escolaridade e frequência mensal de idas aos restaurantes à la carte sobre as variáveis relacionadas às tomadas de decisão durante a escolha do prato.

Na comparação entre sexo e as variáveis relacionadas às tomadas de decisões (Tabela 3), ve- rificou-se que apenas a variável "aspectos sensoriais" apresentou diferença significativa entre os sexos, sendo que os homens atribuem mais importância a esse item que as mulheres. De forma marginalmente significativa ( $p=0,095)$, tem-se que o sexo feminino confere maior importância ao item "sua preferência" que o sexo masculino.

Tabela 3. Medidas descritivas e teste de Mann-Whitney para a importância dos itens do cardápio e frequência nos restaurantes à la carte entre os sexos. Belo Horizonte-MG, Brasil, 2012

\begin{tabular}{|c|c|c|c|c|c|c|c|c|}
\hline Variável & Sexo & $\mathbf{n}$ & Média & E.P. & $1^{\circ} \mathrm{Q}$ & $2^{\circ} \mathrm{Q}$ & $3^{\circ} \mathrm{Q}$ & p - valor \\
\hline \multirow{2}{*}{ Ingredientes } & Feminino & 76 & 0,58 & 0,05 & 0,00 & 0,67 & 1,00 & \multirow{2}{*}{0,869} \\
\hline & Masculino & 29 & 0,56 & 0,08 & 0,00 & 0,67 & 1,00 & \\
\hline \multirow{2}{*}{ Sua preferência } & Feminino & 76 & 0,52 & 0,05 & 0,00 & 0,67 & 1,00 & \multirow{2}{*}{0,095} \\
\hline & Masculino & 29 & 0,36 & 0,08 & 0,00 & 0,00 & 0,67 & \\
\hline \multirow{2}{*}{ Descrição do prato } & Feminino & 76 & 0,19 & 0,04 & 0,00 & 0,00 & 0,17 & \multirow{2}{*}{0,423} \\
\hline & Masculino & 29 & 0,14 & 0,06 & 0,00 & 0,00 & 0,00 & \\
\hline \multirow{2}{*}{ Tamanho do prato } & Feminino & 76 & 0,05 & 0,02 & 0,00 & 0,00 & 0,00 & \multirow{2}{*}{0,222} \\
\hline & Masculino & 29 & 0,12 & 0,05 & 0,00 & 0,00 & 0,00 & \\
\hline \multirow{2}{*}{ Aspectos sensoriais } & Feminino & 76 & 0,22 & 0,04 & 0,00 & 0,00 & 0,50 & \multirow{2}{*}{0,004} \\
\hline & Masculino & 29 & 0,45 & 0,08 & 0,00 & 0,67 & 0,67 & \\
\hline \multirow{2}{*}{ Preço } & Feminino & 76 & 0,21 & 0,03 & 0,00 & 0,00 & 0,33 & \multirow{2}{*}{0,207} \\
\hline & Masculino & 29 & 0,14 & 0,05 & 0,00 & 0,00 & 0,33 & \\
\hline \multirow{2}{*}{ Foto do prato } & Feminino & 76 & 0,03 & 0,02 & 0,00 & 0,00 & 0,00 & \multirow{2}{*}{0,539} \\
\hline & Masculino & 29 & 0,01 & 0,01 & 0,00 & 0,00 & 0,00 & \\
\hline \multirow{2}{*}{ Sugestão do chefe } & Feminino & 76 & 0,07 & 0,02 & 0,00 & 0,00 & 0,00 & \multirow{2}{*}{0,996} \\
\hline & Masculino & 29 & 0,09 & 0,04 & 0,00 & 0,00 & 0,00 & \\
\hline \multirow{2}{*}{ Aspectos nutricionais } & Feminino & 76 & 0,11 & 0,03 & 0,00 & 0,00 & 0,00 & \multirow{2}{*}{0,785} \\
\hline & Masculino & 29 & 0,08 & 0,04 & 0,00 & 0,00 & 0,00 & \\
\hline \multirow{2}{*}{ Métodos de cocção } & Feminino & 76 & 0,03 & 0,01 & 0,00 & 0,00 & 0,00 & \multirow{2}{*}{0,870} \\
\hline & Masculino & 29 & 0,02 & 0,02 & 0,00 & 0,00 & 0,00 & \\
\hline \multirow{2}{*}{$\begin{array}{l}\text { Frequência de idas em restaurantes à } \\
\text { la carte ao mês }\end{array}$} & Feminino & 76 & 4,20 & 0,39 & 2,00 & 3,00 & 5,50 & \multirow{2}{*}{0,218} \\
\hline & Masculino & 27 & 3,96 & 0,78 & 1,50 & 2,00 & 4,00 & \\
\hline
\end{tabular}


Observou-se que o sexo exerce influência significativa na distribuição de frequências sobre a variável "Você consulta o maître" ( $p=$ 0,032). Verificou-se que o sexo masculino tende a consultar menos o maître que o sexo feminino. Interpretando a Razão de Chances, nota-se que o consumidor do sexo masculino tem 0,383 [0,157-0,931] vezes a chance de consultar o maître se comparado com os consumidores do sexo feminino.
De acordo com a Tabela 4, verificou-se que existia uma correlação positiva significativa entre "Sua preferência" e "Descrição do prato" com a idade. Logo, quanto maior era a idade, também maior era a importância dada à preferência e descrição dos componentes do prato no momento da escolha. Além disso, observou-se a existência de uma correlação negativa significativa com o item "Tamanho do prato", visto que quanto maior era a idade menor importância era dada a essa variável.

Tabela 4. Teste de correlação de Spearman entre a importância dos itens do cardápio e frequência nos restaurantes à la carte com a idade dos consumidores. Belo Horizonte-MG, Brasil, 2012

\begin{tabular}{|c|c|c|}
\hline \multirow{2}{*}{ Variáveis } & \multicolumn{2}{|c|}{ Idade } \\
\hline & $r$ & p - valor \\
\hline Ingredientes & $-0,18$ & 0,064 \\
\hline Sua preferência & 0,26 & 0,007 \\
\hline Descrição do prato & 0,20 & 0,041 \\
\hline Tamanho do prato & $-0,20$ & 0,039 \\
\hline Aspectos sensoriais & $-0,10$ & 0,325 \\
\hline Preço & $-0,03$ & 0,748 \\
\hline Foto do prato & $-0,05$ & 0,597 \\
\hline Sugestão do chefe & 0,03 & 0,753 \\
\hline Aspectos nutricionais & $-0,03$ & 0,798 \\
\hline Métodos de cocção & $-0,15$ & 0,116 \\
\hline
\end{tabular}

Verificou-se que as pessoas que analisavam todo o cardápio tendiam a ser mais novas quando comparadas com os consumidores que verificavam apenas os itens de seu maior interesse $(p=0,03)$. Além disso, as pessoas que tentavam reproduzir os pratos que escolheram, em casa, tendiam a ser mais novos quando comparados com os consumidores que não tentavam reproduzir o prato em casa $(p=0,04)$. Verificou-se que dos consumidores que não reproduziam em casa os pratos escolhidos nos restaurantes, pelo menos 50\% possuíam até 39,5 anos, enquanto os consumidores que tentavam fazer em casa os pratos escolhidos nos restaurantes, pelos menos $50 \%$ possuíam até 33 anos.

Foi observado que a importância atribuída ao item "Descrição do prato" apresentou diferença significativa quando comparado ao item escolaridades presente na Tabela 1. Verificou-se que consumidores com escolaridade superior completo atribuem mais importância a esse item que consumidores com escolaridade de até superior incompleto $(p=0,021)$. Além disso, os consumidores que apresentaram menor grau de escolaridade atribuem mais importância ao "tamanho do prato" ( $p=0,021)$ e "aspectos sensoriais" ( $p=0,041$ ) que consumidores com maior grau de escolaridade.

Além disso, a escolaridade apresentou associação significativa com a variável "Você tenta reproduzir o prato que escolheu em casa". Verificou-se que consumidores com maior escolaridade tendem a reproduzir em casa os pratos que escolheram $(34,7 \%)$ menos que os consumidores com menor grau de escolaridade $(78,1 \%)(p=0,001)$. Interpretando a Razão de 
Chances, tem-se que a chance do consumidor da escolaridade até superior incompleto tem $6,71[2,55-17,54]$ vezes a chance de reproduzir em casa o prato que escolheu, se comparado com os consumidores de escolaridade superior completa.

Verificou-se que a frequência de idas aos restaurantes à la carte não exerce influência significativa sobre as variáveis relacionadas às tomadas de decisão dos consumidores no momento das escolhas dos pratos.

Por fim, as informações presentes nos menus dos restaurantes que participaram da pesquisa são apresentadas na Tabela 5. Verificou-se que as informações sobre o preço e descrição dos ingredientes estavam presentes na maioria dos estabelecimentos. Como não há sobreposição dos intervalos de confiança, pode-se afirmar que, pela escala de presença, a variável preço foi mais frequente que a descrição dos ingredientes. Por outro lado, observou-se que informações como declarações nutricionais dos nutrientes e propriedades nutricionais dos ingredientes não estiveram presentes em nenhum dos cardápios avaliados.

Tabela 5. Frequência, média e intervalos de confiança das informações avaliadas. Belo Horizonte-MG, Brasil, 2012

\begin{tabular}{|c|c|c|c|c|c|}
\hline Variável & Média & IC $95 \%$ & Não presente & Em parte & Presente \\
\hline Preço & 0,974 & {$[0,923-1,000]$} & $2,6 \%$ & $0,0 \%$ & $97,4 \%$ \\
\hline Descrição dos ingredientes & 0,705 & {$[0,589-0,821]$} & $15,4 \%$ & $28,2 \%$ & $56,4 \%$ \\
\hline Sugestão do chefe & 0,359 & {$[0,205-0,513]$} & $64,1 \%$ & $0,0 \%$ & $35,9 \%$ \\
\hline Método de cocção & 0,346 & {$[0,244-0,436]$} & $41,0 \%$ & $48,7 \%$ & $10,3 \%$ \\
\hline Sugestão de acompanhamento & 0,269 & {$[0,141-0,423]$} & $71,8 \%$ & $2,6 \%$ & $25,6 \%$ \\
\hline Tamanho da porção & 0,090 & {$[0,026-0,167]$} & $84,6 \%$ & $12,8 \%$ & $2,6 \%$ \\
\hline Ilustração da preparação & 0,051 & {$[0,013-0,103]$} & $89,7 \%$ & $10,3 \%$ & $0,0 \%$ \\
\hline Informação nutricional & 0,026 & {$[0,000-0,077]$} & $97,4 \%$ & $0,0 \%$ & $2,6 \%$ \\
\hline Declaração de nutrientes & 0,000 & {$[0,000-0,000]$} & $100,0 \%$ & $0,0 \%$ & $0,0 \%$ \\
\hline $\begin{array}{l}\text { Declaração de propriedades nutri- } \\
\text { cionais }\end{array}$ & 0,000 & {$[0,000-0,000]$} & $100,0 \%$ & $0,0 \%$ & $0,0 \%$ \\
\hline
\end{tabular}

\section{DISCUSSÃO}

Nesta pesquisa, ficou evidente que o sexo, a idade e a escolaridade interferiram nas escolhas dos pratos e na análise das informações contidas nos cardápios. Isso, por sua vez, demonstra como os aspectos relacionados às questões individuais estão associados ao processo de escolha alimentar. Nesse sentido, Hamilton, et al ${ }^{17}$ citam um modelo no qual categorizam os fatores que influenciam nas escolhas alimentares, sendo que uma dessas categorias é relativa às características do indivíduo, que envolvem o sexo, a idade, a escolaridade, além do conhecimento sobre nutrição e práticas culinárias, bem como a relação entre saúde e alimentação.

Foi interessante observar que o público jovem que frequenta os restaurantes à la carte tenta reproduzir em casa os pratos escolhidos, o que sinaliza para uma possível aproximação entre o ambiente doméstico e o ambiente do restaurante. 
Um exemplo disso é um movimento observado nos Estados Unidos, na Europa e em algumas capitais do Brasil, como São Paulo. Refere-se ao chamado Supper Club ou Restaurante Underground, que consiste no oferecimento de refeições de alta gastronomia em casas particulares e realizadas pelos próprios proprietários. Tal proposta demonstra como, cada vez mais, o cliente procura perpetuar no ambiente domiciliar as experiências vivenciadas nos restaurantes. Outro fato relevante é o crescimento de supermercados especializados denominados "gourmet". Esse nicho pretende atender pessoas que buscam novos ingredientes e opções para compor suas refeições no domicílio. Essa procura parte, principalmente, das sensações adquiridas nos restaurantes como os à la carte.

Ressalta-se que a tendência constatada na presente pesquisa pode, também, ser explicada pela intensa midiatização da gastronomia, ou seja, o aumento expressivo do número de veículos, como livros, revistas, cadernos de grandes jornais, programas televisivos e sítios eletrônicos, todos voltados para a divulgação e ensinamento da culinária. Ademais, percebe-se grande procura por cursos de ensino superior em gastronomia. Segundo dados divulgados pelo Ministério da Educação e Cultura ${ }^{18}$, atualmente tal curso está entre os dez mais buscados pelos vestibulandos. Nesse contexto, nota-se a valorização dos profissionais envolvidos nessa área, como os chefes de cozinha. No Brasil e no restante do mundo, os chefes têm ganhado grande notoriedade, exercendo o mesmo fascínio que atores renomados de cinema exercem.

Todas essas questões discutidas, por sua vez, influenciam principalmente a população mais jovem, uma vez que está sempre à procura de enquadrar-se nas últimas novidades existentes, sejam elas referentes à moda, à aquisição de produtos eletrônicos, bem como às inclinações sociais. Percebe-se, então, que esse comportamento contribui para o crescimento e disseminação desse novo hábito.

Outra questão relevante dessa pesquisa é que as informações mais presentes nos menus dos restaurantes avaliados foram o preço, a descrição dos ingredientes e a sugestão do chefe. Num outro sentido, verificou-se que, para tomar a decisão em relação ao que iriam consumir, os usuários de restaurantes à la carte consideraram, além de suas preferências, as características sensoriais dos pratos, informações pobremente exploradas nos menus. Dessa forma, observou-se como há um descompasso entre as informações veiculadas nos cardápios e o que de fato determina as escolhas dos usuários.

O cliente, ao se decidir por determinado tipo de alimento, encontra-se previamente regido por aspectos socioculturais e por experiências individuais e, nessas últimas, estão incluídas também aquelas relacionadas à construção do paladar. Jomori, et al ${ }^{19}$ destacam que, mesmo o homem sendo dotado da condição onívora, ou seja, condição em que permite alimentar-se de todo tipo de alimento, ao decidir-se sobre o que irá consumir, se baseia no que é aceito pela cultura do grupo no qual se insere.

Nesse sentido, Von Atzingen e Pinto ${ }^{20}$ reforçam como as características sensoriais dos alimentos determinam as preferências e aversões alimentares, sendo essas desenvolvidas durante a infância e adolescência e perpetuando durante toda a vida. Em outra abordagem, Dória ${ }^{21}$ explica que o paladar deve ser entendido na sua forma mais ampla, ou seja, como uma junção dos cinco sentidos: o gustativo, regido pelo próprio sabor; o olfativo, representado pelo aroma dos alimentos; o visual, expressado pelas formas, volumes e cores; o tátil, que corresponde à sensação do alimento sendo mastigado; e o auditivo, referente ao som que produz. Após esse detalhamento, o autor explica que o indivíduo somente fará sua escolha quando todos os sentidos forem atendidos.

Essas referências, tal como a presente pesquisa, indicam que os clientes, ao fazerem suas escolhas alimentares, apoiam-se em um fator que dificilmente será traduzido num cardápio: sua preferência pessoal. Nesse caso, a própria lógica de divulgação prévia de opções em uma lista fechada como os cardápios se apresenta, confronta uma demanda efetiva dos clientes, que desejam, na realidade, escolher algo mais personalizado.

Além da preferência pessoal, essa pesquisa também revelou a importância dos aspectos sensoriais nas escolhas de alimentos em restaurantes à la carte. Esse fator, ao contrário do 
tema anterior, pode e deve ser bem explorado pelo profissional que é responsável pelo cardápio.

Nessa direção, de modo a reforçar ainda mais essa hipótese, Tinoco e Ribeiro ${ }^{22}$, em seu estudo qualitativo sobre os principais determinantes da qualidade e do preço percebidos por clientes de restaurantes à la carte, observou que o preço compreendido por esses se pautam menos pelos elementos monetários e mais pelas questões que envolvem a qualidade do serviço, do ambiente e da comida.

De maneira similar, na presente pesquisa, notou-se que os clientes pouco consideraram os aspectos nutricionais das preparações. Pode-se deduzir que o ato de se alimentar fora do lar comporta-se muito mais como forma de entretenimento e sociabilidade. Heck $^{23}$ ressalta que sair de casa para comer expressa a vontade individual de interagir socialmente, ou seja, o comer fora representa uma forma de o indivíduo se apresentar perante a sociedade e reforçar seus laços sociais. Barbieri, et al ${ }^{24}$ verificaram que $85 \%$ dos entrevistados de sua pesquisa, ao se defrontarem com informações nutricionais, não deixaram de consumir algum alimento, mesmo que esses pudessem ter representado algum risco para saúde.

Dessa forma, tais estudos confirmam que o processo de escolha alimentar é determinado mais por questões muitas vezes subjetivas e pessoais do que por informações presentes nos menus.

Na direção contrária, destaca-se que, mesmo os usuários pautando suas decisões por informações não presentes nos cardápios, as pessoas analisam todo o menu antes de efetivarem suas escolhas alimentares, justificando, então, a relevância do melhoramento da estruturação dessas listas de iguarias.

$\mathrm{Na}$ presente pesquisa, observou-se que grande parte dos usuários analisa todo o cardápio antes de realizar o pedido, entretanto, notou-se que muitos ainda não compreendem os termos empregados. Pode-se inferir que o não entendimento dos termos do menu pelos usuários impulsiona-os a consultarem o maitre. Tais atitudes demonstram como os clientes estão receptivos a novas experiências e cada vez mais procuram por diferentes sensações no campo da culinária, mesmo ainda não familiarizados com os termos gastronômicos empregados nos cardápios.
De acordo com dados do IBGE ${ }^{9}$, percebe-se como há, desde a década de 2000, uma diminuição da desigualdade social. Isso, por sua vez, tem possibilitado um maior acesso da população em atividades de lazer antes não frequentemente vivenciadas, entre elas a utilização do serviço de restaurantes à la carte. Assim, percebe-se que a criação de um novo hábito traz consigo o não conhecimento de termos que pautam as escolhas. Além disso, vale ressaltar que essa nova prática alimentar abre campo de pesquisa para novas atitudes alimentares, bem como, em estudos futuros, analisar o impacto dessas recentes incorporações nos âmbitos sociais, culturais e nutricionais.

\section{CONCLUSÃO}

Os clientes de restaurantes à la carte participantes dessa pesquisa eram jovens, com alto nível de escolaridade e estavam em busca de novos conhecimentos e experiências à mesa. Nesse sentido, o sexo dos participantes, a idade e o grau de escolaridade foram determinantes na composição do percurso de tomadas das decisões de usuários de restaurantes à la carte.

As informações presentes nos menus não impactavam diretamente no processo decisório dos clientes. As escolhas das pessoas perpassavam a subjetividade individual, bem como a representatividade social do ato alimentar.

Ademais, observou-se que o comer nos restaurantes à la carte está se tornando uma atividade de entretenimento mais acessível, e as experiências adquiridas nesses locais estão sendo reproduzidas no âmbito doméstico, o que sugere uma mudança de padrão alimentar.

Diante da eclosão desse novo hábito, a temática estudada na presente pesquisa abre campo para futuros estudos sobre a efetividade das informações presentes nos cardápios e o impacto desses novos comportamentos nas escolhas alimentares.

A respeito das escolhas pautadas pelas preferências pessoais, sugere-se tentar aproximar as alternativas do interesse do cliente ou mesmo permitir certo nível de customização da comida. Outro percurso seria reforçar a proposta do restaurante atraindo, por meio da oferta, os clientes que tenham maior tendência a identificar-se com os itens dos cardápios. 
Em relação à importância dada pelo cliente aos aspectos sensoriais dos pratos, a inclusão nos menus de expressões tais como "legumes crocantes" ou "molho levemente adocicado" podem ter impacto relevante nas escolhas. Nesse sentido, além de ingredientes simplesmente declarados, talvez deva prevalecer a descrição sensorial dos pratos, visto que, da forma como os cardápios são apresentados, podem conter informações pouco úteis e até mesmo desnecessárias.

\section{REFERÊNCIAS}

1. IBGE. Instituto Brasileiro de Geografia e Estatística. Síntese de indicadores sociais - Uma análise das condições de vida da população brasileira 2012. Rio de Janeiro: IBGE; 2012 [acesso 24 Out 2013]. Disponível em: http://www.ibge.gov.br/ home/estatistica/populacao/condicaodevida/indicadoresminimos/sinteseindicsociais2012/.

2. Branco NSDC, Salay E. Attitude of consumers in relation to eating out in the commercial center of Rio de Janeiro, Brazil. Food Res Int. 2001;13(1):57-65. DOI: http://dx.doi.org/10.1111/j.1745-4506.2001.tb00029.x.

3. Sanches M, Salay E. Alimentação fora do domicílio de consumidores do município de Campinas, São Paulo. Rev Nutr. 2011 [acesso 5 Nov 2013];24(2):295-304. Disponível em: http://www.scielo.br/scielo.php?pid=S141552732011000200010\&script=sci arttext. DOI: http://dx.doi.org/10.1590/S1415-52732011000200010.

4. Leal D. Crescimento da alimentação fora do domić́lio. Rev Segurança Alim Nutr. 2010 [acesso 24 Set 2013];17(1):12332. Disponível em: http://www.unicamp.br/nepa/san.php?pag=san vol 171 artigo 11.php.

5. Lelis CT, Teixeira KMD, Silva NM. A inserção feminina no mercado de trabalho e suas implicações para os hábitos alimentares da mulher e de sua família. Saúde Debate. 2012 [acesso 4 Nov 2013];36(95):523-32. Disponível em: http:// www.scielo.br/scielo.php?script=sci arttext\&pid=S010311042012000400004\&lng=pt\&nrm=iso\&tlng=en. DOI: http:// dx.doi.org/10.1590/S0103-11042012000400004.

6. Associação Brasileira das Empresas de Refeições Coletivas. Mercado real de refeições. São Paulo: ABERC; 2010 [acesso 20 Set 2013]. Disponível em: http://www.aberc.com.br/mercadoreal.asp?IDMenu=21.

7. Associação Brasileira das Indústrias da Alimentação. Balanço anual 2012 e perspectivas para 2013. São Paulo: ABIA; 2012 [acesso 4 Set 2013]. Disponível em: http://www.abia.org.br/vst/32.asp.

8. International Monetary Fund. World Economic Outlook Database. 2008 [acesso 25 Out 2013]. Disponível em: http:// www.imf.org/external/pubs/ft/weo/2009/02/weodata/index.aspx.

9. IBGE. Instituto Brasileiro de Geografia e Estatística. Pesquisa de orçamentos familiares 2008-2009: análise do consumo alimentar pessoal no Brasil. Rio de Janeiro: IBGE; 2011 [acesso 15 Out 2013]. Disponível em: http://www.ibge.gov.br/ home/estatistica/populacao/condicaodevida/pof/2008 2009 analise consumo/pofanalise 2008 2009.pdf.

10. Federação das Indústrias do Estado de São Paulo - FIESP. Brasil Food Trends 2020. 2010 [acesso 15 Set 2013]. Disponível em: http://www.brasilfoodtrends.com.br/publicacao.html.

11. EUFIC. European Food Information Council. Os determinantes na escolha dos alimentos. Rev EUFIC. 2005;17:1-7. Disponível em: http://www.eufic.org/article/pt/page/RARCHIVE/expid/37/.

12. Lachin JM. Introduction to sample size determination and power analysis for clinical trials, 1981. Control Clin Trials. 1981;2(2):93-113. DOI: http://dx.doi.org/10.1016/0197-2456(81)90001-5.

13. Fleiss JL. The design and analysis of clinical experiments. New York: John Wiley \& Sons; 1986.

14. Hollander M, Douglas AW. Nonparametric statistical methods, solutions manual. 2nd ed. New York: Wiley Series in Probability and Statistics John Wiley \& Sons; 1999.

15. Siegal S, Castellan Jr NJ. Estatística não-paramétrica para ciências do comportamento. 2a ed. Porto Alegre: Artmed; 2006. 448 p.

16. Bolfarine H, Bussab WO. Elementos de amostragem. São Paulo: Editora Edgard Blucher; 2005.

17. Hamilton J, Mcllveen H, Strugnell C. Educating young consumers - a food choice model. J Consumer Studies Home. 2008;24(2):113-23. DOI: http://dx.doi.org/10.1046/j.1365-2737.2000.00151.x.

18. Ministério da Educação e Cultura. Cadastro da educação superior. [acesso 24 Out 2013]. Disponível em: http://emec. mec.gov.br/.

19. Jomori MM, Proença RPC, Calvo MCM. Determinantes de escolha alimentar. Rev Nutr. 2008 [acesso 9 Dez 2013];21(1):63-73. Disponível em: http://www.scielo.br/scielo.php?script=sci arttext\&pid=S141552732008000100007\& lng=pt\&nrm=iso\&tlng=pt. DOI: http://dx.doi.org/10.1590/s1415-52732008000100007.

20. Von Atzingen MCBC, Silva MEMP. Características sensoriais dos alimentos como determinante das escolhas alimentares. Nutrire. 2010 [acesso 20 Out 2013];35(3):183-96. Disponível em: http://www.revistanutrire.org.br/articles/ view/id/4fa15d1c1ef1fa4f5000000b.

21. Dória CA. A culinária materialista: a construção racional do alimento e do prazer gastronômico. São Paulo: Editora Senac; 2009. 
22. Tinoco MAC, Ribeiro JLD. Estudo qualitativo dos principais atributos que determinam a percepção de qualidade e de preço dos consumidores de restaurantes à la carte. Gestão Produção. 2008 [acesso 5 Out 2013];15(1):73-87. Disponível em: http://www.scielo.br/scielo.php?script=sci arttext\&pid=S0104530X2008000100008\&lng=pt\&nrm=iso\&tlng=pt. DOI: http://dx.doi.org/10.1590/s0104-530x2008000100008.

23. Heck MC. Comer como atividade de lazer. Rev Estudos Históricos. 2004 [acesso 7 ago 2013];33:136-46. Disponível em: http://bibliotecadigital.fgv.br/ojs/index.php/reh/article/viewArticle/221.

24. Barbieri T, Rodrigues KS, Silva SF, Medeiros LB, Saccol ALF. Consumer attitudes toward information displayed at food buffets in commercial restaurants. Food Sci Technol. 2012 [acesso 15 Set 2013];32(4):798-803. Disponível em: http:// www.scielo.br/scielo.php?script=sci arttext\&pid=S010120612012000400024\&lng=en\&nrm=iso\&tlng=en. DOI: http:// dx.doi.org/10.1590/s0101-20612012005000104. 